\title{
Bilateral Piriformis Syndrome Following a Treadmill Injury
}

\author{
Pelin YILDIRIM, ${ }^{1}$ Osman Hakan GÜNDÜZ, ${ }^{2}$ Yeşim GARİP, ${ }^{3}$ Tülay ÖZER ${ }^{4}$ \\ ${ }^{1}$ Department of Physical Medicine and Rehabilitation, Kocaeli Derince Training and Research Hospital, Kocaeli, Turkey \\ ${ }^{2}$ Department of Physical Medicine and Rehabilitation, Medical Faculty of Marmara University, İstanbul, Turkey \\ ${ }^{3}$ Department of Physical Medicine and Rehabilitation, Başak Medical Center, Ankara, Turkey \\ ${ }^{4}$ Department of Radiology, Kocaeli Derince Training and Research Hospital, Kocaeli, Turkey
}

A 52-year-old female patient was referred to the clinic with complaints of bilateral buttock and leg pain for the last one year. In the initial interview, the patient complained of bilateral buttock pain radiating to both legs without improvement despite the use of nonsteroidal anti-inflammatory drugs and physical therapy. Her complaints started after a traumatic injury. Upon detailed questioning, she mentioned she had fallen on her buttocks severely after adjusting the treadmill to a high speed and altering the treadmill's incline settings during her first use. The patient's medical history was not notable except for a cholecystectomy three years earlier. On physical examination, there was a full active range of motion of all the lower limb joints and the lower back. Bilateral hip movements were painful with bilateral hip flexion and internal rotation. The straight leg raise test was positive on the left and right at 60 and 50 degrees, respectively. Her neurological and neurovascular examinations were normal. In addition, complete blood count, routine blood biochemistry, and acute phase reactants were within normal range. Bilateral piriformis syndrome was suspected after exclusion of the other pathologies using electrodiagnostic studies and lumbar magnetic resonance imaging. Her physical examination was repeated. She had tenderness to external palpation over greater sciatic notches on both sides. Flexion+adduction+internal rotation, Beatty, and Pace tests were positive bilaterally. Pelvis magnetic resonance imaging documented that both sciatic nerves were increased in intensity in the axial and coronal short-tau inversion recovery sequences (Figure 1a and b). After obtaining informed consent, the patient was administered an ultrasound-guided injection of $4 \mathrm{~mL}$ lidocaine $2 \%$ and $1 \mathrm{~mL}$ betamethasone dipropionate into both piriformis muscles using a 22G $88-\mathrm{mm}$ spinal needle. ${ }^{1}$ After the procedure, her pain decreased substantially (pre- and post-treatment visual analog scale scores for pain were 8 and 4 , respectively). In the light of these findings, the patient was diagnosed with bilateral piriformis syndrome. Further treatments, including the spray and stretch technique, were incorporated two times as the pain was maintained at a visual analog scale level of $4 / 10 .^{2}$ At the six-week follow-up, she was completely asymptomatic. On physical examination, piriformis-specific tests were also negative for both sides.

Piriformis syndrome is an entrapment neuropathy of the sciatic nerve at the level of the piriformis muscle. ${ }^{3}$ An ultrasound-guided injection of local anesthetics and steroids into the piriformis muscle may contribute to both diagnostic and therapeutic aims. ${ }^{1}$ In this case, based on the

Received: June 24, 2015 Accepted: July 09, 2015 Published online: August 10, 2015

Correspondence: Pelin Yildirim, MD. Kocaeli Derince Eğitim ve Araştırma Hastanesi Fiziksel Tıp ve Rehabilitasyon Kliniği, 41900 Derince, Kocaeli, Turkey.

Tel: +90 532 - 3801078 e-mail: drpeliny@gmail.com

○2015 Turkish League Against Rheumatism. All rights reserved. 

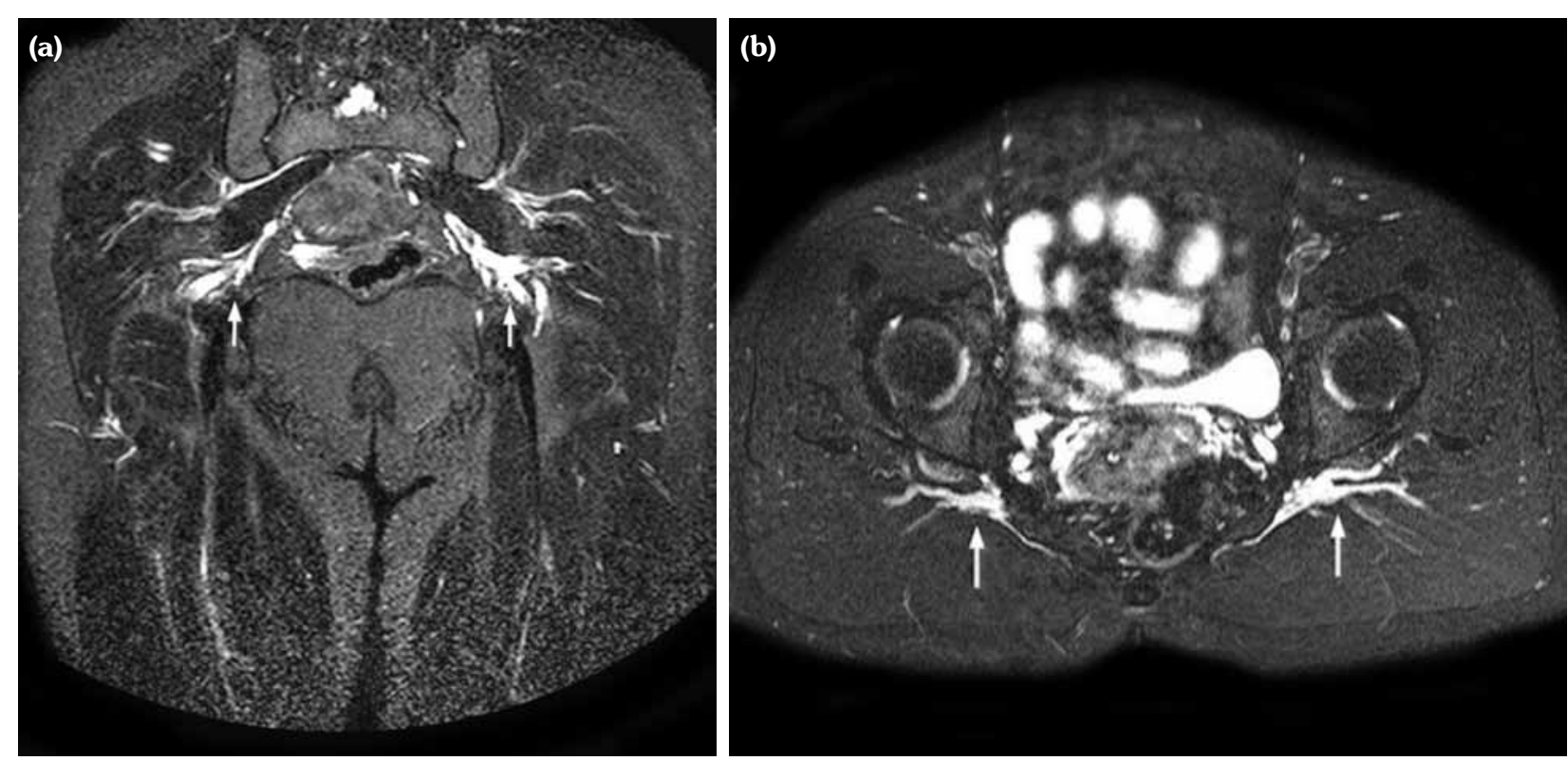

Figure 1. (a) Axial short-tau inversion recovery image showing a marked increase in signal intensity in both sciatic nerves, left more severe than right (arrow). (b) Coronal short-tau inversion recovery image showing increased size and intensity of both sciatic nerves, left more severe than right (arrows).

abnormal findings from the magnetic resonance imaging, a corticosteroid-anesthetic mixture was injected into the piriformis muscles. The relief of the symptoms following the injection confirmed the diagnosis and provided an effective treatment. It is assumed that the resolution of the patient's complaints after the injection might be the result of the anti-inflammatory action of the steroid.

Making differential diagnosis of sciatica may be quite complex. Although piriformis syndrome is known as a cause of sciatica, bilateral piriformis syndrome is a rare phenomenon. Our report suggests that piriformis syndrome following a trauma may be causally related to the development of bilateral sciatica.

\section{Declaration of conflicting interests}

The authors declared no conflicts of interest with respect to the authorship and/or publication of this article.

\section{Funding}

The authors received no financial support for the research and/or authorship of this article.

\section{REFERENCES}

1. Hopayian K, Song F, Riera R, Sambandan S. The clinical features of the piriformis syndrome: a systematic review. Eur Spine J 2010;19:2095-109.

2. Pecina HI, Boric I, Smoljanovic T, Duvancic D, Pecina M. Surgical evaluation of magnetic resonance imaging findings in piriformis muscle syndrome. Skeletal Radiol 2008;37:1019-23.

3. Kostopoulos D, Rizopoulos K. Effect of topical aerosol skin refrigerant (spray and stretch technique) on passive and active stretching. J Bodyw Mov Ther 2008;12:96-104.

4. Smith J, Hurdle MF, Locketz AJ, Wisniewski SJ. Ultrasound-guided piriformis injection: technique description and verification. Arch Phys Med Rehabil 2006;87:1664-7. 